\title{
Experience with a LiveCD in an education process
}

\author{
Jan Růžička, František Klímek \\ Institute of Geoinformatics \\ Faculty of Mining and Geology, VSB-TUO \\ E-mail: jan.ruzicka@vsb.cz
}

Key words: LiveCD, GISák LiveCD, Distance Learning, E-learning

\begin{abstract}
The paper describes how can be LiveCD (Bootable CD) used for geoinformatics distance learning. We have prepared one LiveCD with basic software for learning geoinformatics and we have some feedback from users and teachers. The paper should evaluate this feedback. LiveCD is a CD-ROM, that can be used as a bootable device. After booting from the CD, the user can access all resources compiled to the CD. There are operating system (usually based on GNU/Linux) and (user, desktop) software installed and configured to be used directly after boot. Our CD named GISák LiveCD contains basic GIS software such as UMN MapServer, GRASS, Quantum GIS, Thuban, JUMP, GPS Drive, Blender and we work on other software packages such as MapLab for UMN MapServer, PostGIS, GeoNetwork Open Source, CatMDEdit, gvSIG, uDIG. GISák LiveCD contains set of spatial data from the Czech Republic. Main part of the CD are tutorials for GIS software. CD is open for other e-learning materials. Now we have about 20 students using our LiveCD and few other users that are not curently our students. The paper should show Pros $\&$ Cons of the LiveCD usage for a distance learning.
\end{abstract}

\section{LiveCD}

Live CD is bootable CD-ROM with operating system and installed and configured programs. It is ready to use as full installed system directly after boot from CD-ROM drive. There is more than one hundred distributions of Live CD. We can say that there is a few targeted to the GIS users. Most well known Live CD in the GIS area is called GIS-KNOPPIX. That Live CD can be used for education, research, testing, etc. But there are two aspects that made our decision to do not use that Live CD in the Czech Republic. Last distribution of the CD is not for free of charge at this time and the CD works with data mainly for the USA.

\section{GISák LiveCD}

\section{Background}

At the beginning we have to describe how came the idea of the project to our mind. It was not quick process, it comes quite slowly. In the autumn of the 2003 came new wave of thinking to the institute of geoinformatics. Before that period we have used open source software only rarely. We used GIS open source software for "playing" only, but not for serious work. We worked with GRASS and UMN MapServer. After the autumn 2003 some of us 
have completely moved to the OS Linux (thanks to Michal and Pavel) and we have started using the open source as a platform for our day work.

In these days first projects based on open source have fired up. They have been related to the current teaching of some subjects. For example it was GVSB_View project in the subject of Java programming or it was project that moves subject called "Software for GIS II" from close source (and commercial) software to the open source (and free) software.

Nowadays in a lot of study subjects is used open source software and other teachers are thinking about using open source for teaching. The main reason is (but i only suggest, you have to ask them) that they would like to give a chance to our students to do not use cracked software. Common student have not got enough money to buy a licence for GIS software (of course there is some commercial software free of charge for students, but usually you have to apply for a grant or do any other non popular things). When student would like to do his homework lessons, he (or she) has to either come to our laboratory (where the licensed software is available) or use cracked software.

Well, if a teacher think in the way such as: I will prepare my exercises to suit for example GRASS system, because my students can use it free of charge: we can say that it is not so easy. Some of the software are not available for common OS (Windows) or it is very difficult to install them on it. That reason was one of our impulses for GISák LiveCD.

Another impulse came from second level of education. We are cooperating with some high schools and they are thinking about GIS. But the software is expensive, data are not available, etc.

Nowadays we are using open source quite often and once somebody made a question: "What we are giving to open source community? We only use the products and do no give in back any to it". That was another impulse.

That were the reasons in a short review. Let us show you list of project's goals described in a different way than in the abstract of the paper:

- Give the set of open source software to our students in one compact form

- Give the tutorial data and set of tools to high schools in one compact form

- Prepare set of useful tutorials for used software

- Prepare data from the Czech Republic available free of charge

- Advertise open source GIS tools

- Advertise OS Linux

\section{Project stages}

1. September 2004 - first ideas

2. January 2005 - first version for internal tests (Based on Linux4All [3])

3. April 2005 - first official version (Based on Linux4All) 
4. January 200 - special edition for GIS Ostrava 2006 (Based on Kanotix-mini [2])

5. October 2006 - second version distributed via GI journal (plans) (Based on Kanotix or Knoppix [4] or who knows)

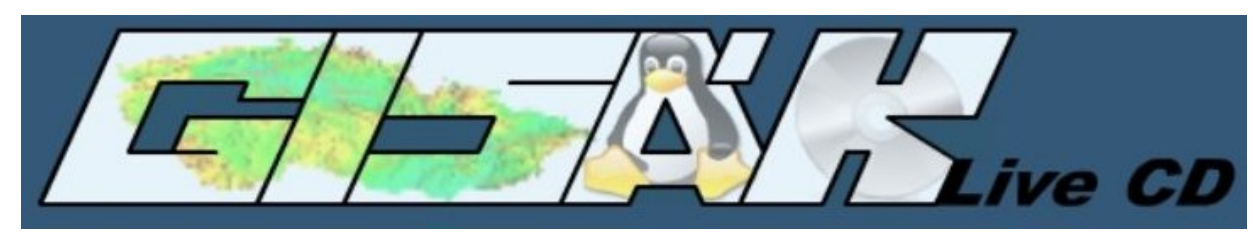

Figure 1: Logo GISák LiveCD

\section{Data}

GISák LiveCD contains free geodata. There are Spearfish dataset and geodata collected by Martin Landa ${ }^{1}$. We plan to include some data measured by our students and other geodata from public sources.

\section{Software}

GISák LiveCD contains following software:

- GRASS 6

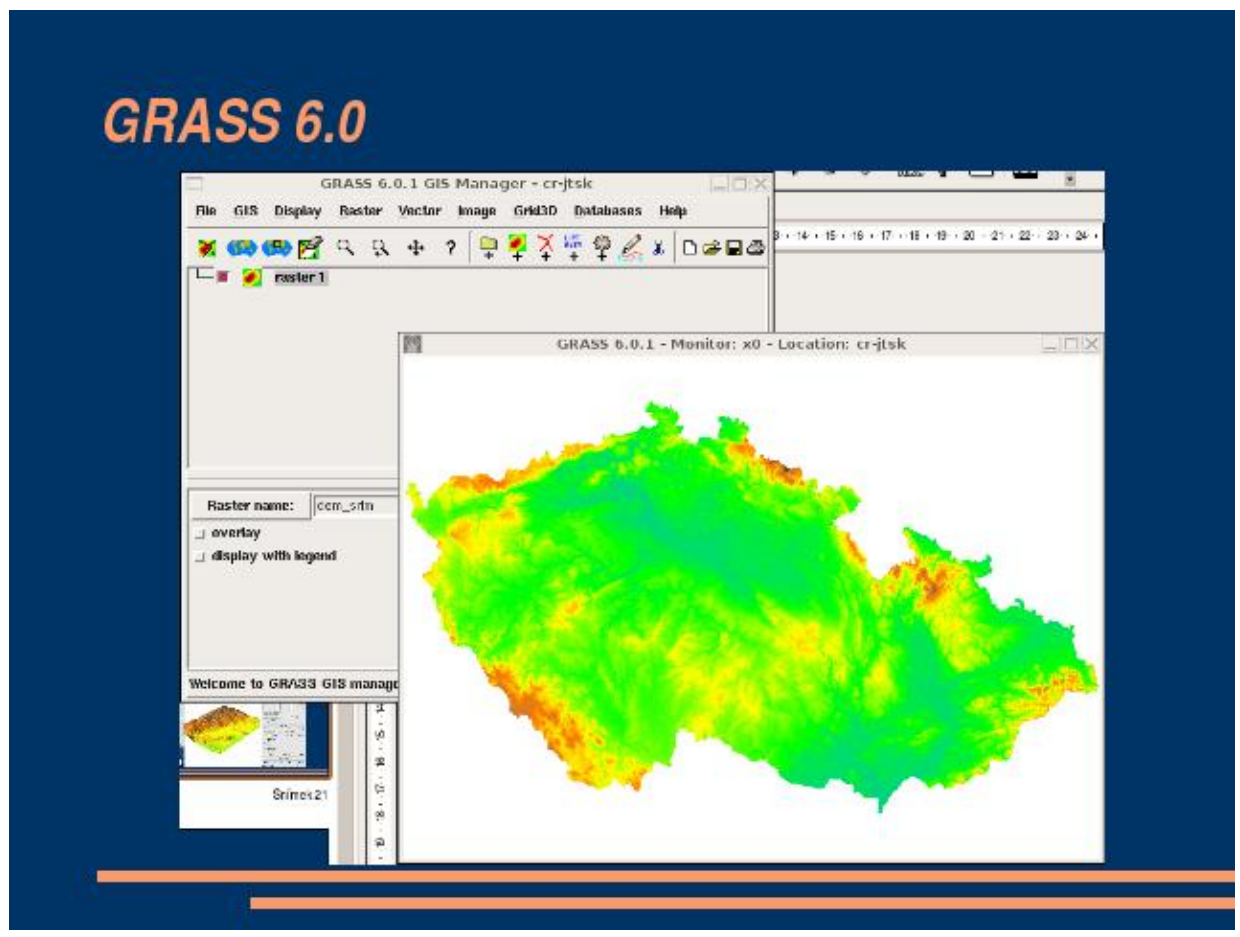

Figure 2: GRASS 6

\footnotetext{
${ }^{1}$ http://grass.fsv.cvut.cz/wiki/index $\cdot p h \mid$ p/Geodata_CZ
} 
- JUMP 1.2

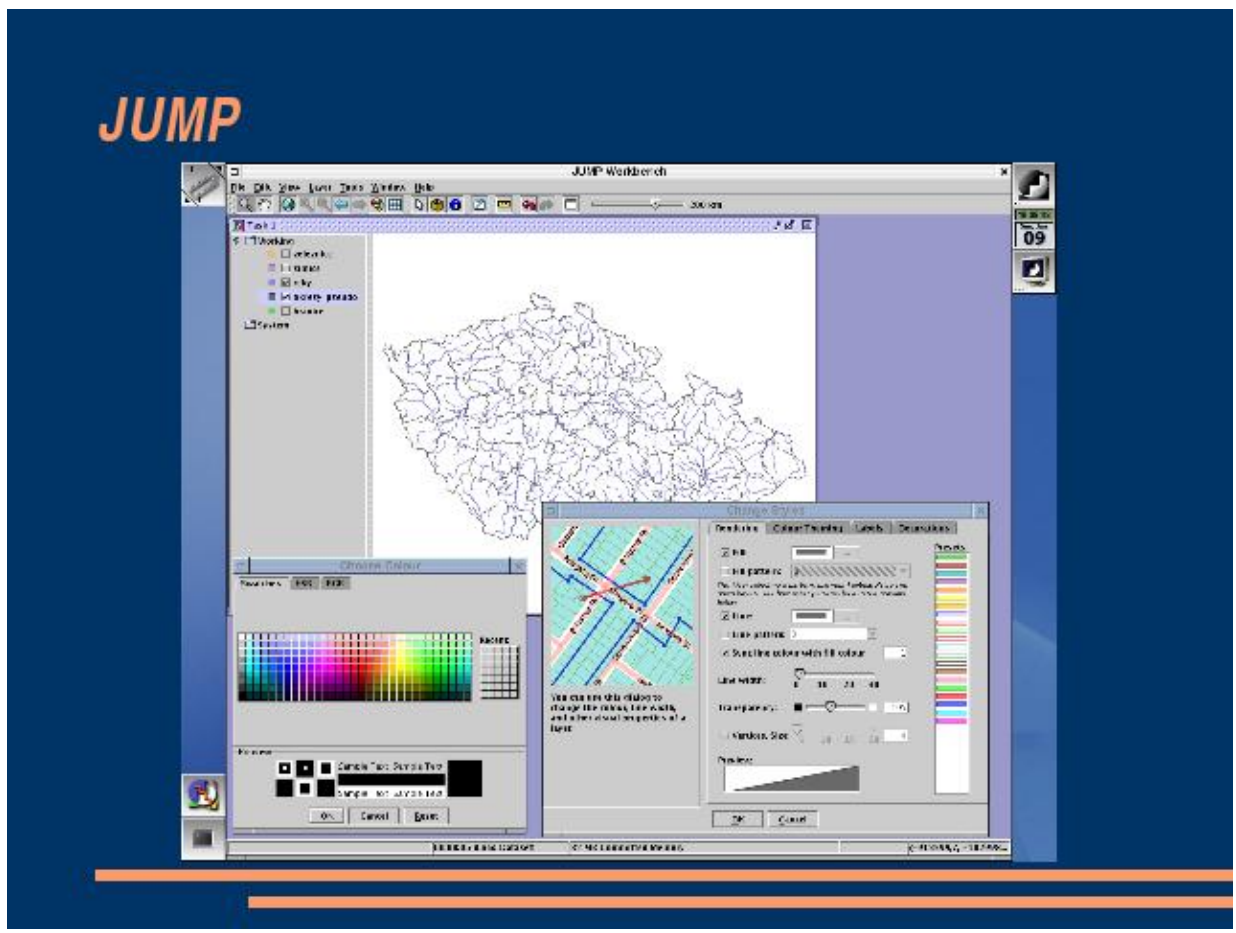

Figure 3: JUMP

- QGIS 0.6

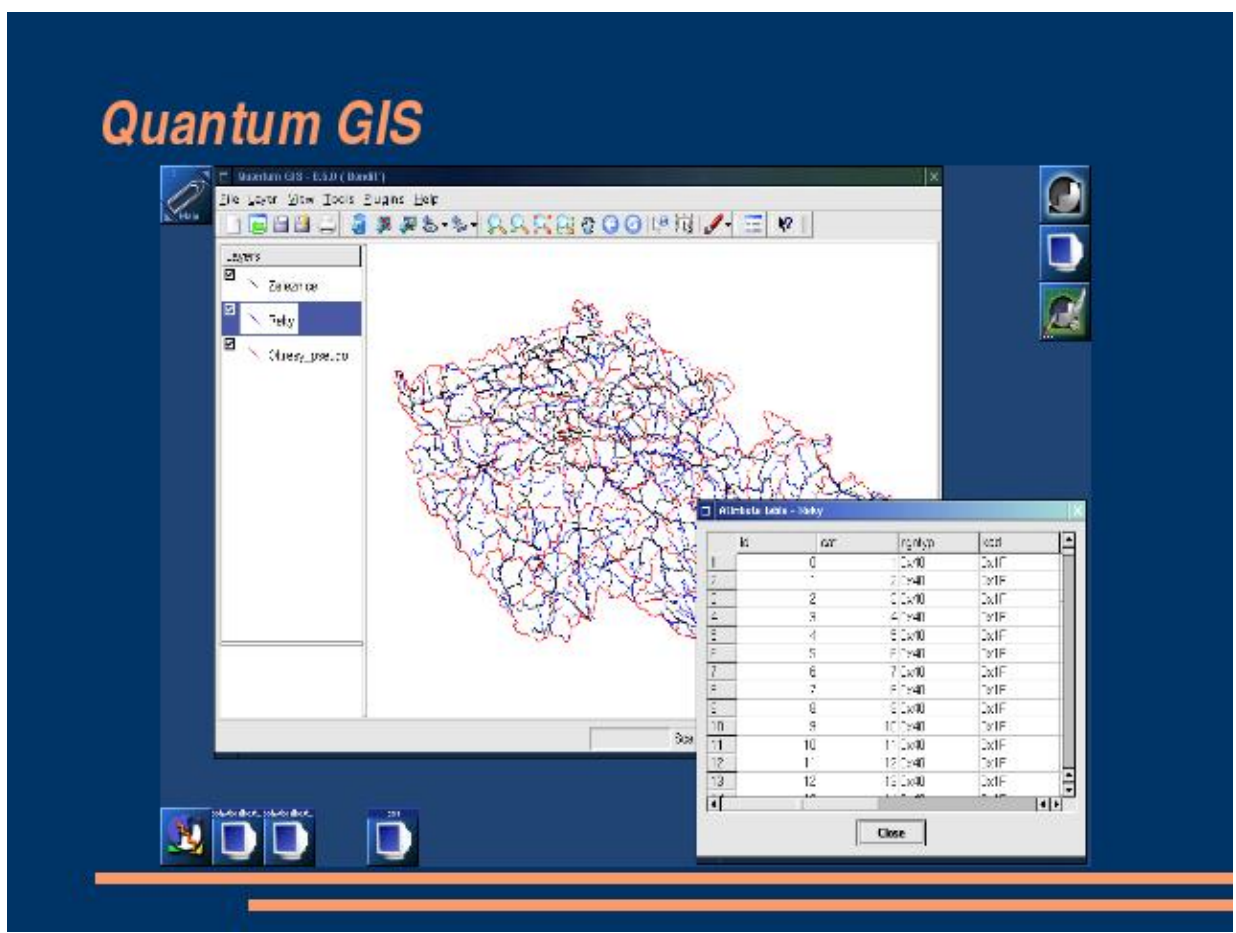

Figure 4: QGIS 
- Thuban

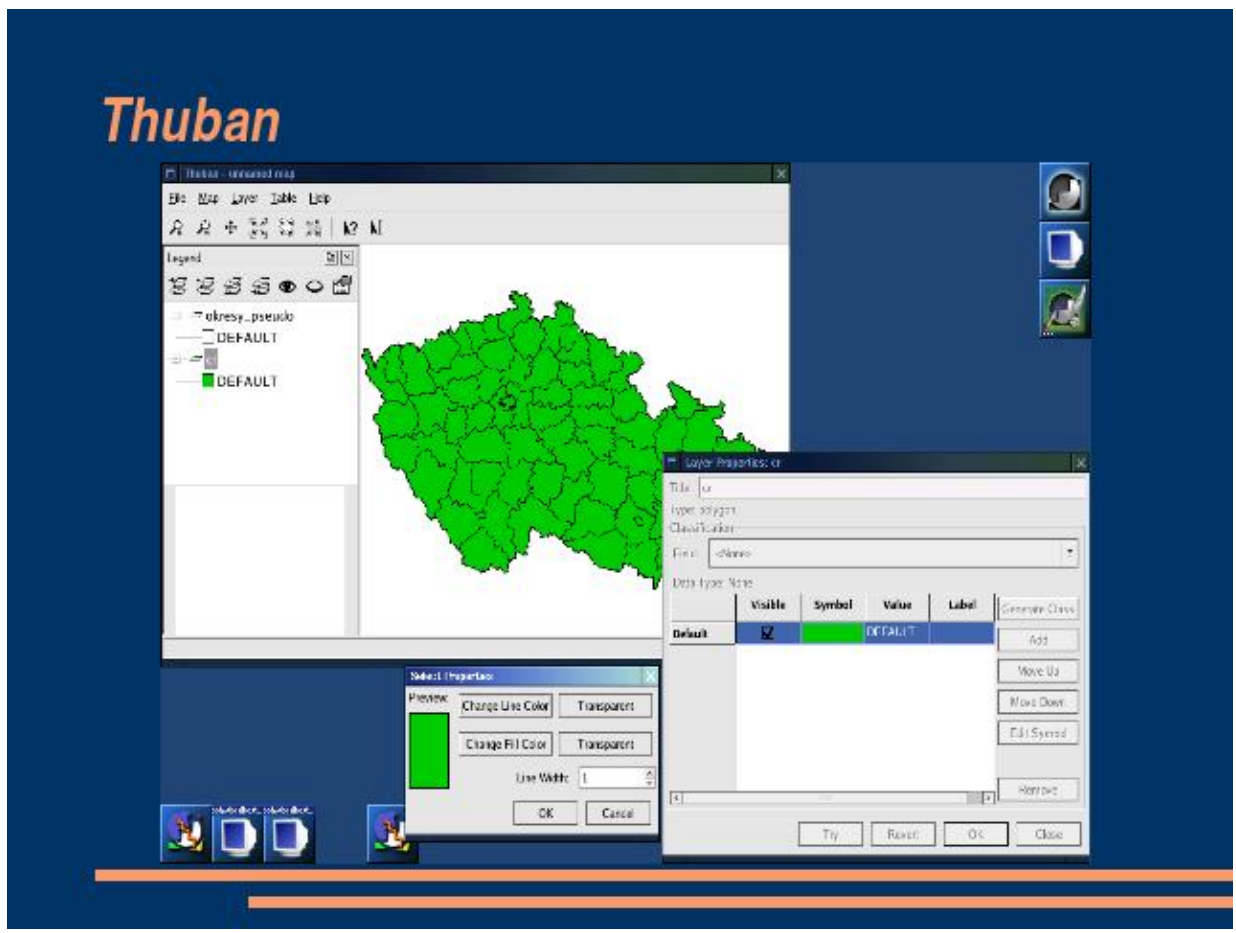

Figure 5: Thuban

- GPS Drive

- UMN Map Server 4.2

- Blender

We plan to add following software:

- $\mathrm{uDIG}$

- gvSIG

- PostGIS

- GeoNetwork Open Source

- CatMDEdit

\section{Tutorials}

There are few tutorials for GRASS, JUMP, Thuban and QGIS software, but we plan to add other tutorials and regural materials prepared by other teachers or students. 


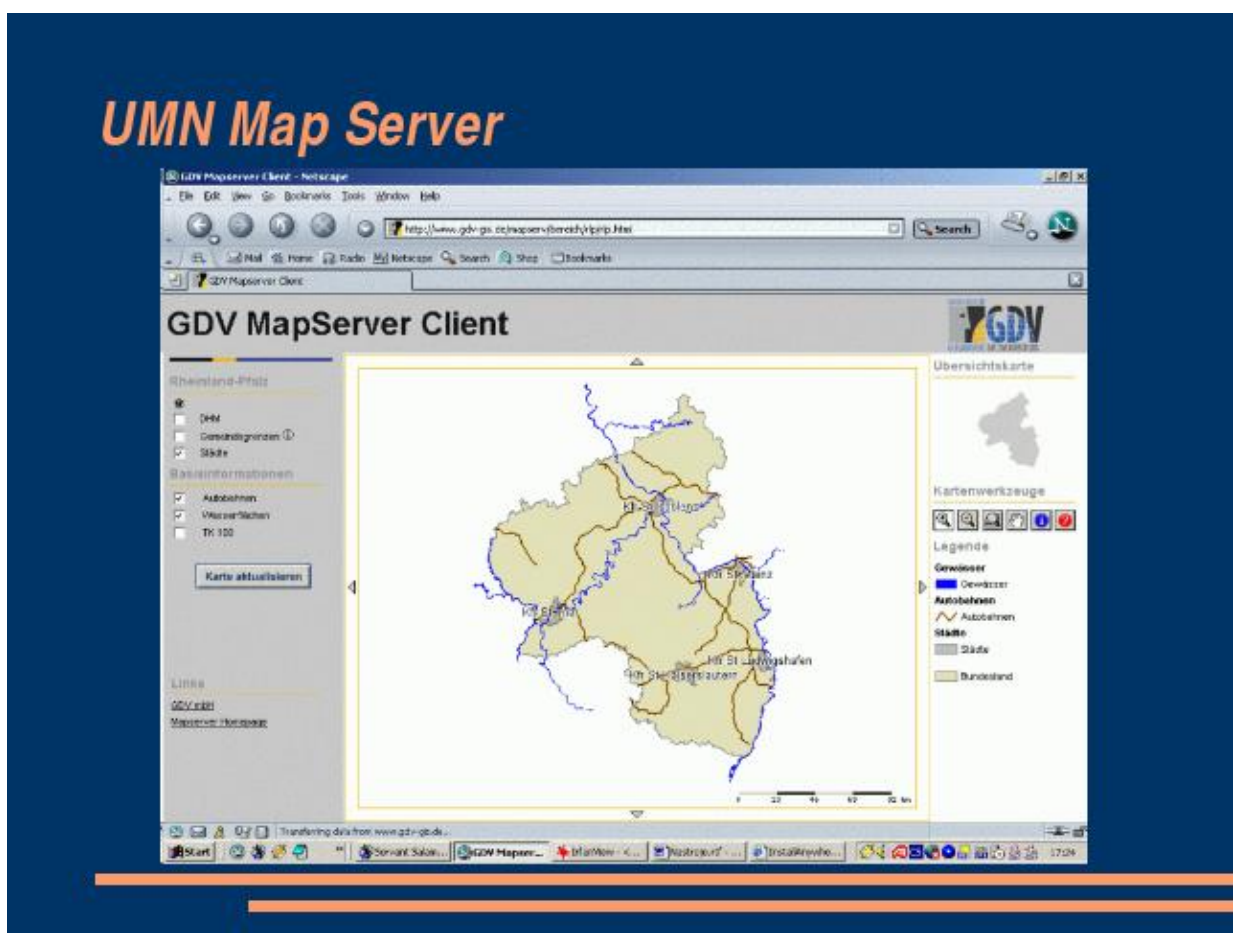

Figure 6: UMN MapServer

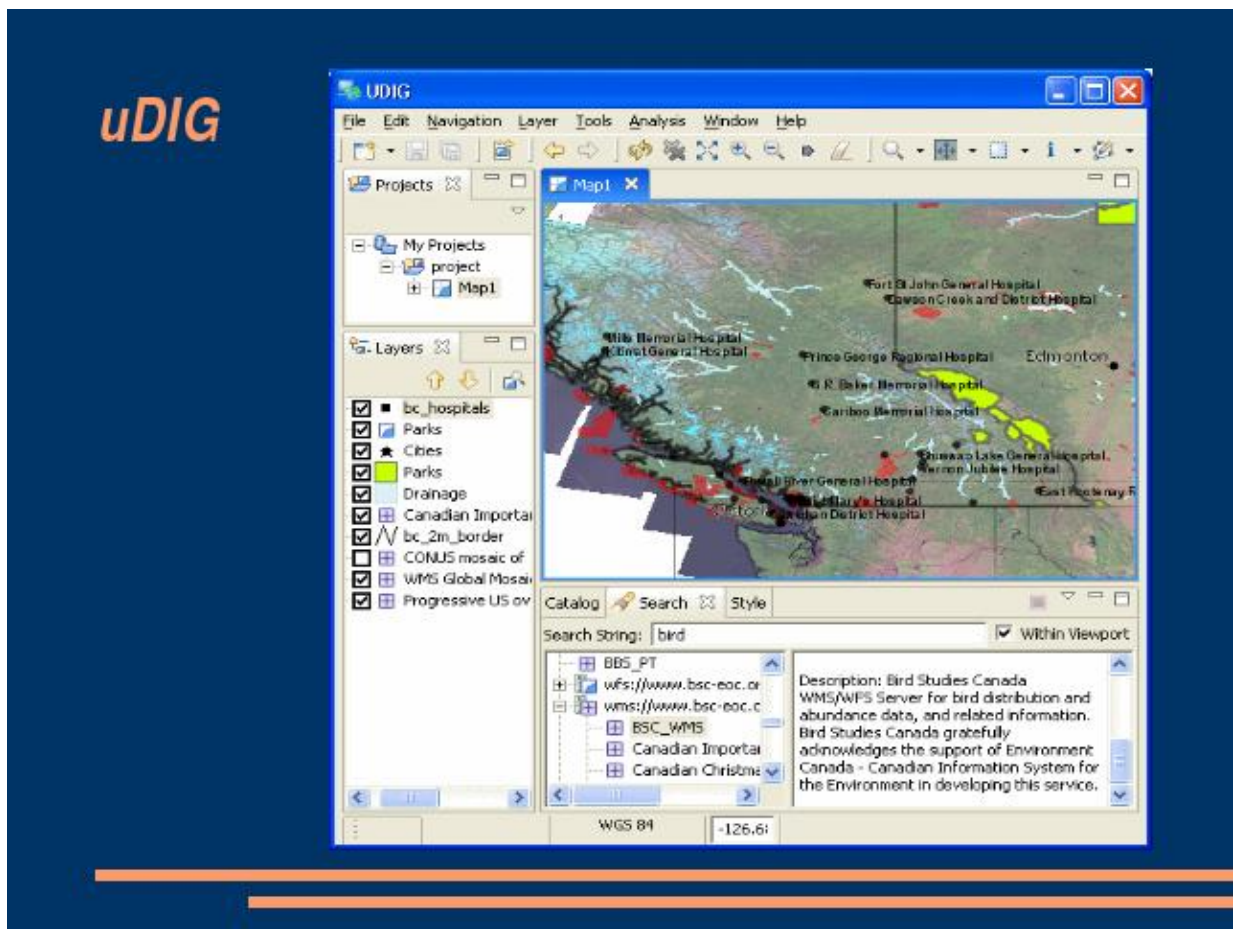

Figure 7: uDIG

\section{Distance, E-Learing using LiveCD}

We have experiences with a distance learning using e-learning techniques. For example our institute offers three e-learning courses. Courses' students can access learning materials on 


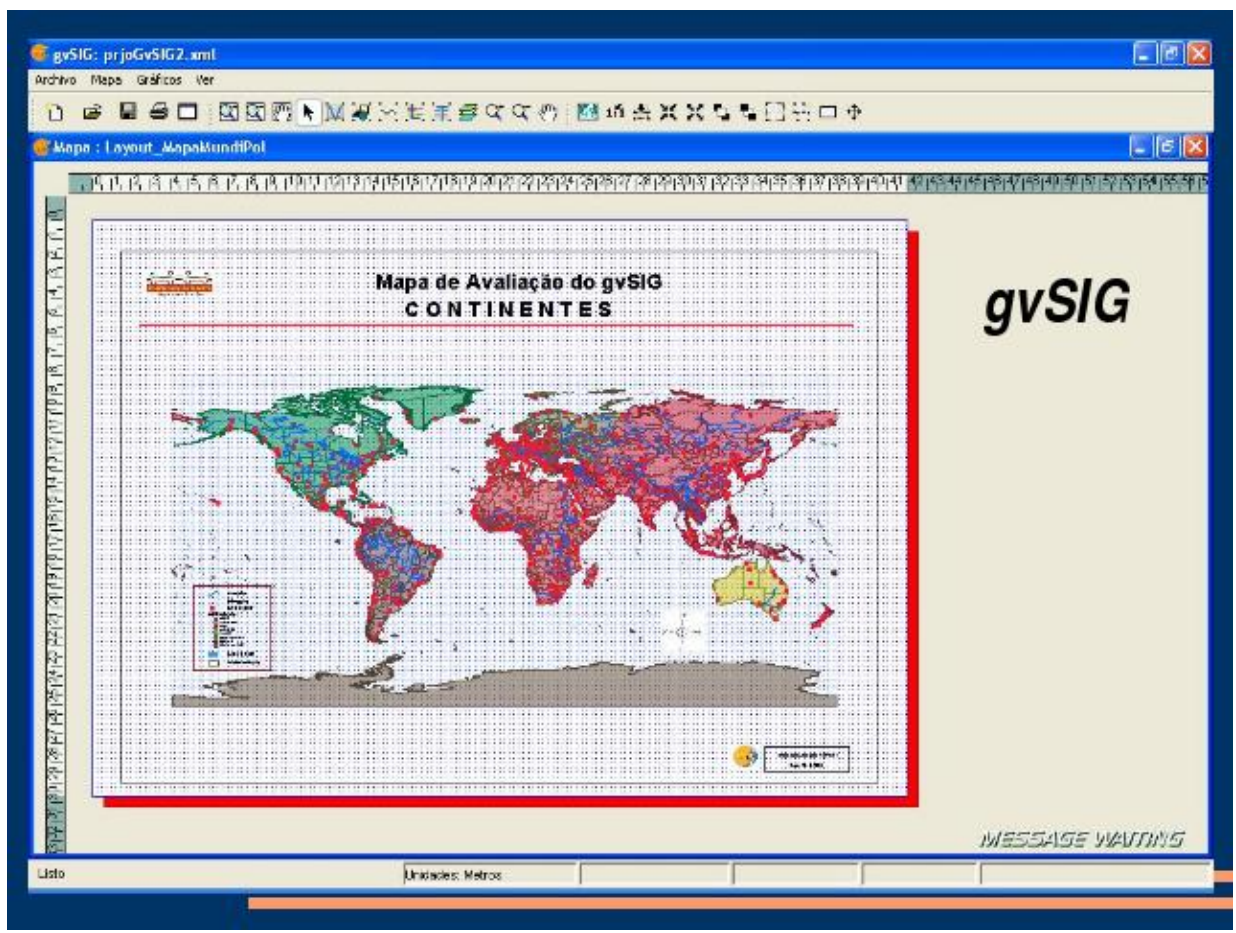

Figure 8: gvSIG

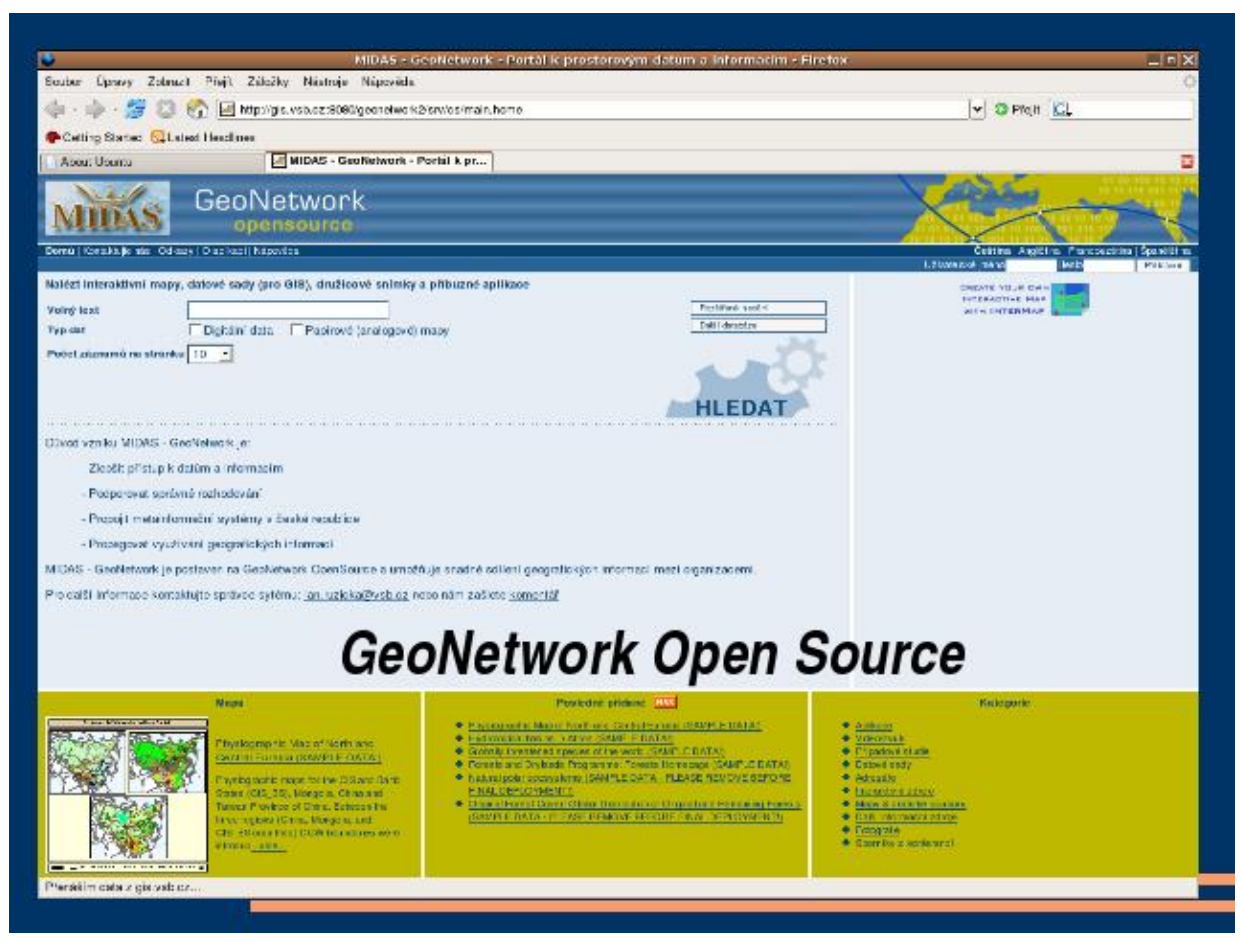

Figure 9: GeoNetwork Open Source

web (interactive e-learning system Barborka [15]) or use static CD with learning materials in multimedia form. But some of the excersies need software installation, configuration and other problematic tasks. We have bad experiences with this way of e-learning. Many of our 


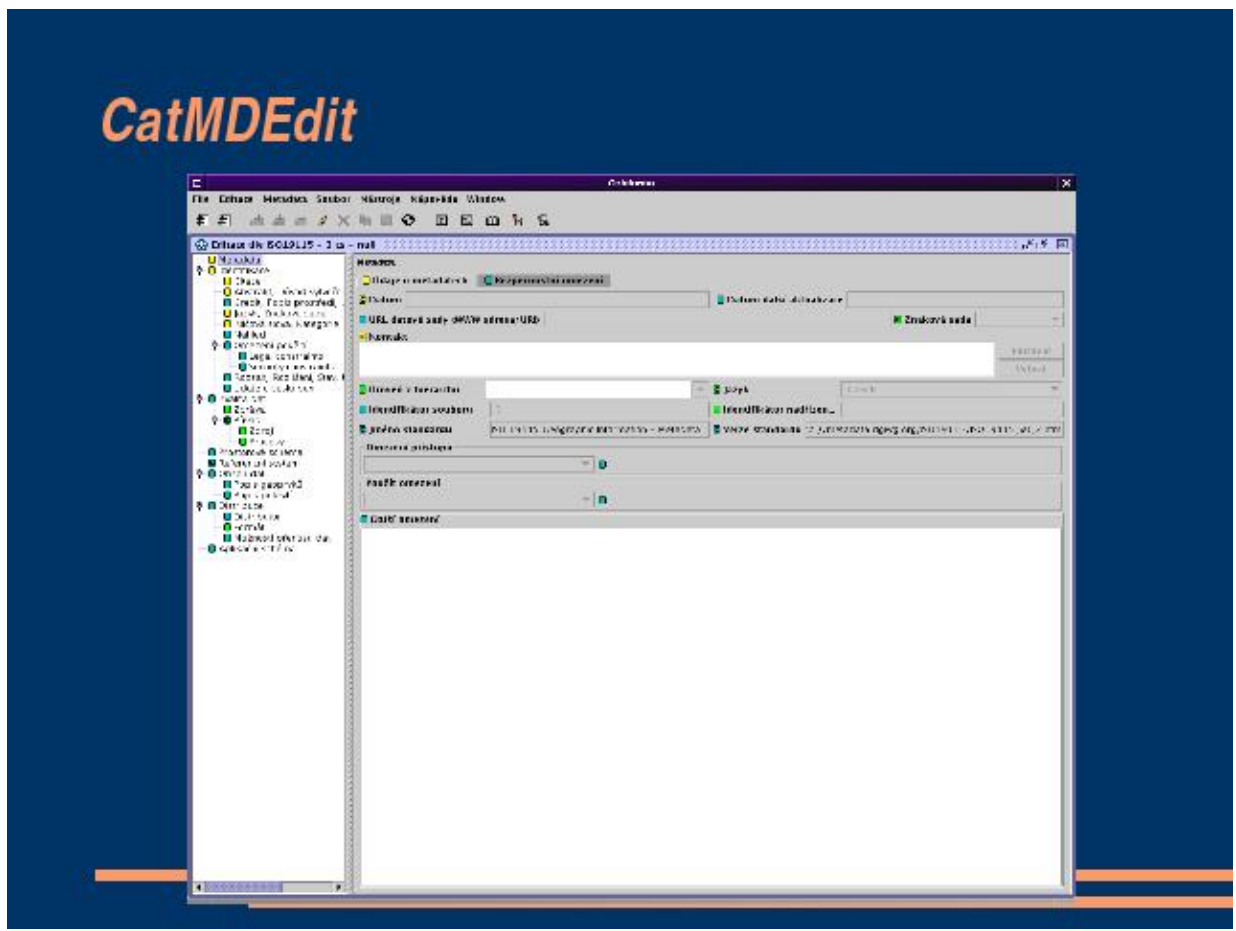

Figure 10: CatMDEdit

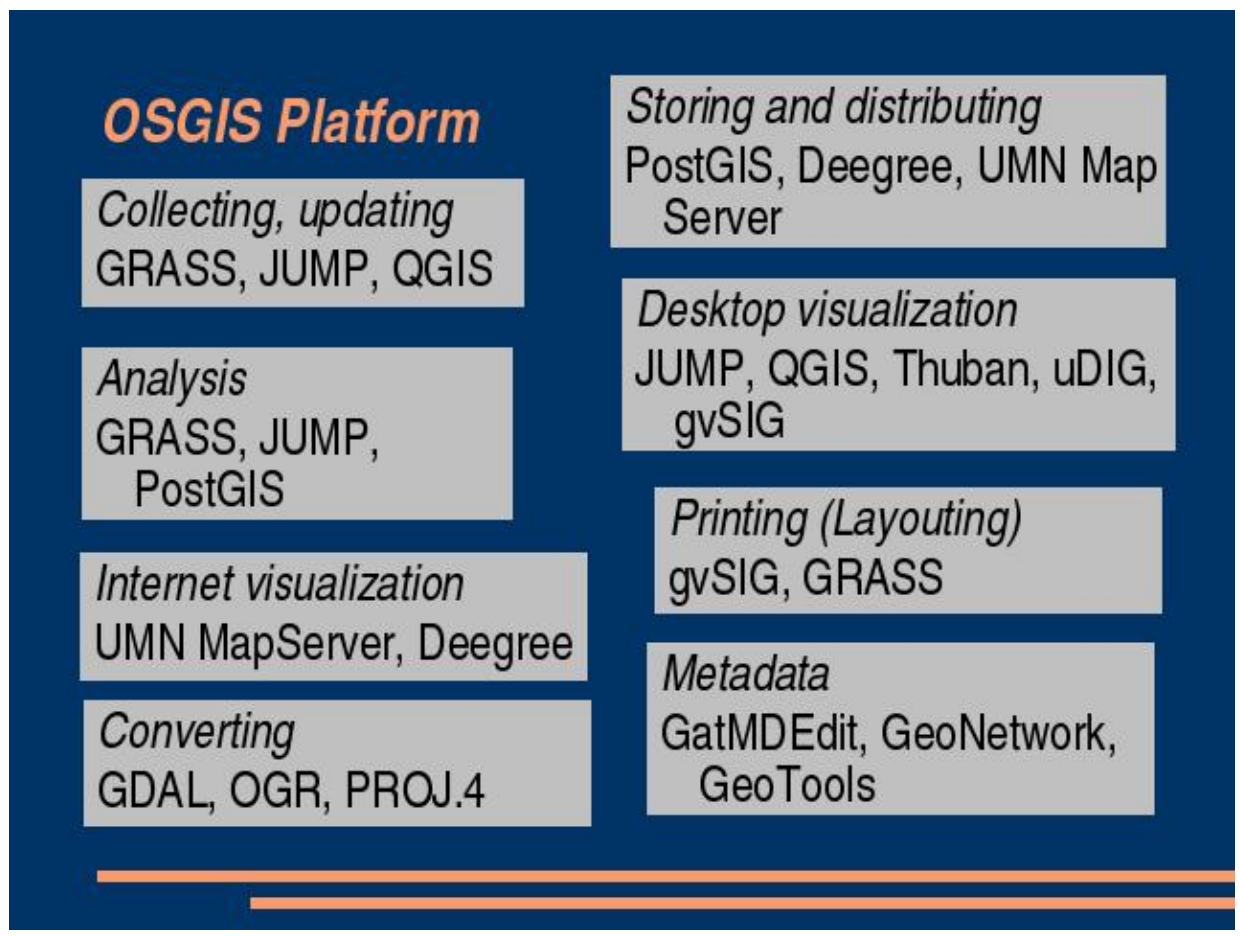

Figure 11: Open SOurce GIS Platform

students had difficulties with installing and configuring software available on CD. They have different OS, different conditions (for example some of them are not administrators of their PCs used for education and they can not install software) and installing instructions can not 
handle all platforms and all possible problems.

We can minimalize such problems using LiveCD. All software is installed, configured and students can concentrate on necessary tsaks only.

\section{Users' experiences}

Here are listed some of the users' experiences using GISák LiveCD:

- problems on some PCs/Notebooks - usually solved by boot options

+ better than standalone - that was a quite big surprise

- problems with importing data v.in.ogr - we have tried import DGN and everyting went well, the user did not specify aditional information needed for handling his problem

+ do not need install whole system to handle one or two subjects

+ possibility to distribute diploma thesis in a live form

\section{Users' requirements}

Here are listed some of the users' requirements using GISák LiveCD:

- Knowledge base - How to for specific tasks - Tutorials can go to impasse

- Write on NTFS

- Save state - users would like to pause their work and continue after new boot with state saved in some permanent memory (Flash, HD)

- Need help with boot options - some PCs needs to set up boot options before booting, but it is not so easy for not experienced user to set up them correctly. We should distribute some brochure that describes how to set up boot options for some list of devices

\section{Teachers' experiences}

+ Very useful on roads

+ Prepared same conditions for all students

+ Compact form - data and software on one place

+ Useful when network is not available

\section{Teachers' requirements}

- Tools for updating configuration without burning a new CD - on-line - LiveCD will download configuration during booting from the web site

- Tools for installing new software - on-line - Make own LiveCD compilation 


\section{Pros \& Cons}

+ Free available tools

+ Prepared data

+ Prepared configuration - Workshops, Competitions

+ Integrated data with software

+ Useful when network is not available - Workshops, Competitions

- Update CD - need every time you change the content

- Never better than standalone installation - except some situations

\section{Conclusion}

- LiveCD is useful when other options are not available and that conditions are common

- LiveCD brings same conditions for all students

- LiveCD brings possibilities to integrate data, software and study materials to one compact form

- Solution based on LiveCD is limited by CD updating - burning a CD is not so convenient

\section{What can do students with LiveCD}

Students can use LiveCD to perform following tasks (or will soon) and all of them are available on software from Open Source GIS Platform

- Geodata collecting, updating

- Geodata storing and distributing

- Geodata analysis

- Geodata visualization: Desktop, Internet, Printing

- Geodata describing: metadata management

- Geodata converting: coordinate, formats

\section{Future work}

- Prepare DVD - with more data

- Prepare USB image - no burning necessary

- Prepare tools for more user (teacher) friendly CD updating

- Integrate other study materials 


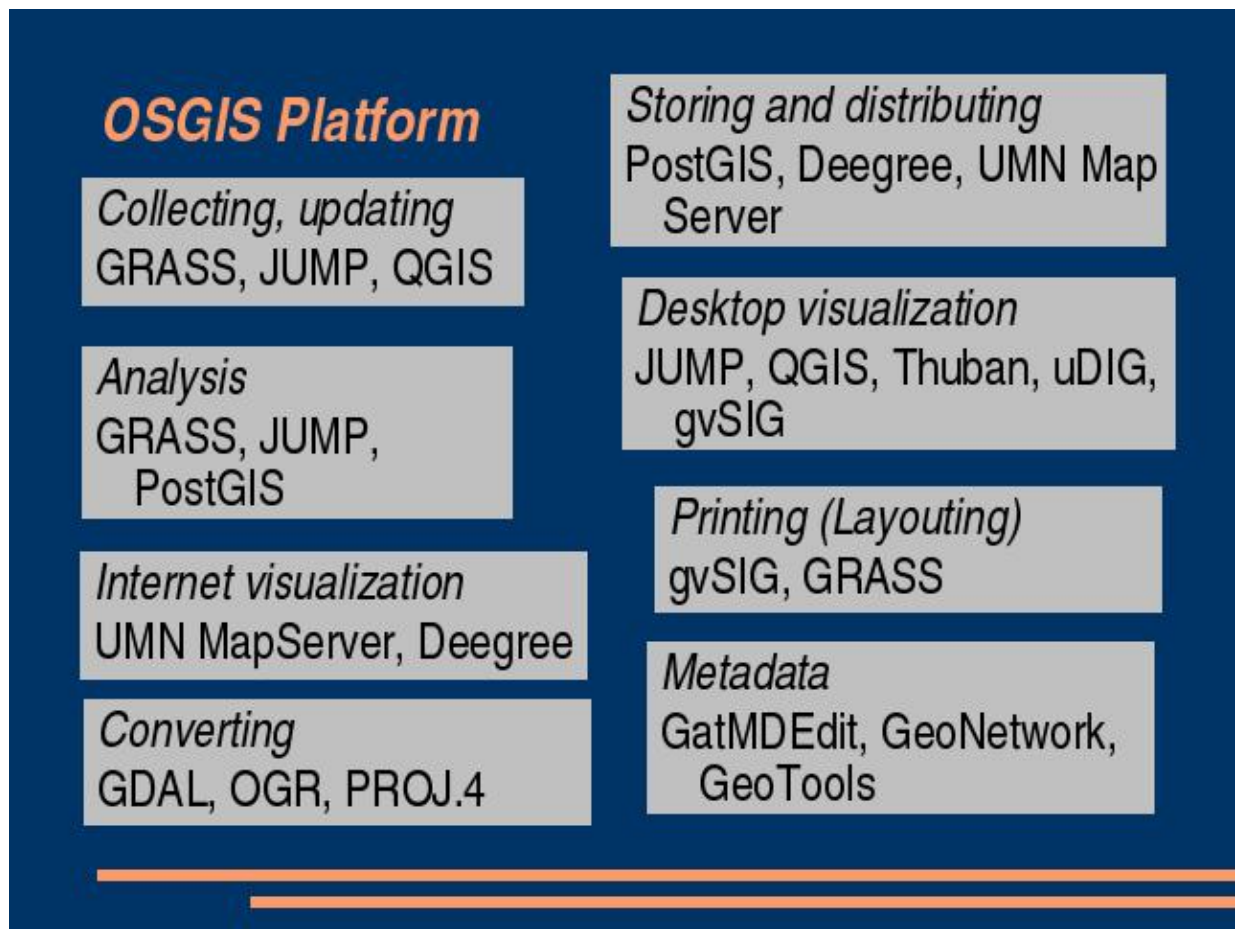

Figure 12: Open Source GIS Platform

- Prepare other software

- ...

\section{References}

1. Růžička J., Klímek F., Děrgel P., Šeliga M. GIS on Linux4All - Live CD. In Sborník z konference GIS Ostrava 2005, Ostrava, 2005, ISSN 1213-239X. Dostupný na: WWW2

2. Kanotix Home Page ${ }^{3}$ - Kanotix Home Page

3. Linux4All. Linux4All. 2004. Available on $\mathrm{WWW}^{4}$

4. Source Pole. GIS-Knoppix. 2004. Available on $\mathrm{WWW}^{5}$

5. GRASS Development Team. GRASS GIS. 2004. Available on WWW6

6. QGIS.org. Quantum GIS. 2004. Available on $\mathrm{WWW}^{7}$

7. Thuban Project Team. Thuban. 2004. Available on WWW

\footnotetext{
${ }^{2}$ http://gis.vsb.cz/Publikace/Sborniky/GIS_Ova/GIS_Ova_2005/Sbornik/Referaty/ruzicka.htm

${ }^{3}$ http://kanotix.com/files/kanotix/

${ }^{4}$ http://www.linux4all.de/livecd

${ }^{5}$ http://www . sourceple.com/gis-knoppix

${ }^{6}$ http://grass.itc.it/

${ }^{7}$ http://www.qgis.org/

${ }^{8}$ http://thuban.intevation.org/
} 
8. The JUMP Project. JUMP Unified Mapping Platform. 2004. Available on WWW ${ }^{9}$

9. Regents of the University of Minnesota. UMN MapServer. 2004. Available on WWW ${ }^{10}$

10. MapTools.org. MapLab. 2004. Available on WWW ${ }^{11}$

11. PostGIS.org. PostGIS. 2004. Available on WWW 12

12. Ganter F. GPS Drive. 2004. Available on WWW ${ }^{13}$

13. Orlík A., Růžička J., Stromský J., Děrgel P., Kamler J. Správa časoprostorových dat v prostředí PostgreSQL/PostGIS, sborník z konference Open Weekend 2005, Praha 15. 16.10.2005, ISBN 800103349X

14. Růžička J. Workshop Open Source GIS. Available on WWW $W^{14}$

15. Trio Team 2003 from VSB-TUO. Barborka. Available on $\mathrm{WWW}^{15}$

\footnotetext{
${ }^{9}$ http://www.jump-project.org/

${ }^{10}$ http://mapserver.gis.umn.edu/

${ }^{11}$ http: //www . maptools .org/maplab/index . phtml

12 http://www.postgis.org/

${ }^{13}$ http://gpsdrive.kraftvoll.at/

${ }^{14}$ http://gis.vsb.cz/ruzicka/Seminare/OpenSource/index.php

${ }^{15}$ http://barborka.vsb.cz/lms/
} 